\title{
Distribution of DRB1 and DQB1 HLA class II alleles in occupational asthma due to western red cedar
}

\author{
C. Horne*, P.J.E. Quintana**, P.A. Keown*, ${ }^{,+}$H. Dimich-Ward ${ }^{++}$, M. Chan-Yeung ${ }^{++}$
}

Distribution of DRBI and DQB1 HLA class II alleles in occupational asthma due to western red cedar. C. Horne, P.J.E. Quintana, P.A. Keown, H. Dimich-Ward, M. ChanYeung. (C)ERS Journals Ltd 2000.

ABSTRACT: Occupational asthma caused by western red cedar is a common problem in sawmill industries. The objective of this study was to examine a possible association of human leukocyte antigen (HLA) class II genetic markers with susceptibility or resistance to western red cedar induced asthma.

The distribution of DRB1 and DQB1 HLA class II alleles and DRB1-DQB1 haplotypes was studied in 56 Caucasian patients with proven red cedar asthma and 63 healthy Caucasian control subjects exposed to red cedar dust. DRB1 and DQB1 high resolution typing was performed by the polymerase chain reaction-based method.

Patients with red cedar asthma had a higher frequency of HLA DQB1*0603 and DQB1*0302 alleles compared to a group of healthy exposed control subjects and a reduced frequency of $D Q B 1 * 0501$ allele. The frequency of the DRB1*0401-DQB1* 0302 haplotype was increased and the DRB1*0101-DQB1*0501 haplotype was reduced.

These findings suggest that genetic factors such as human leukocyte antigen class II antigens may be associated with susceptibility or resistance to development of red cedar asthma.

Eur Respir J 2000; 15: 911-914.
*Immunology Laboratory, Vancouver Hospital and Health Sciences Centre, Vancouver, Canada. **San Diego State University, Graduate School of Public Health, San Diego, CA, USA. ${ }^{+}$Dept of Medicine, University of British Columbia, Vancouver, Canada. ${ }^{++}$Occupational Lung Diseases Research Unit, Respiratory Division, Dept of Medicine, University of British Columbia, Vancouver, Canada.

Correspondence: M. Chan-Yeung, Respiratory Division, Dept of Medicine, University of British Columbia, 2775, Heather St., Vancouver, B.C. Canada, V5Z 315. Fax: 0016048754695

Keywords: Human leukocyte antigen class II antigens

occupational asthma

Received: March 151999

Accepted after revision January 122000
Many agents capable of causing occupational asthma are small molecular weight compounds, including isocyanates and plicatic acid (the agent responsible for western red cedar asthma (WRCA)) [1]. Although they have been extensively studied, the mechanisms responsible for occupational asthma are unclear. There is a latent period between onset of exposure and the onset of symptoms, and re-exposure of sensitized subjects to a very small amount of the offending agent often induces a severe attack of asthma. Specific immunoglobulin (Ig)E antibodies have either not been detected or have been found in only a small proportion of affected patients [2, 3], even though the features of these two conditions are highly suggestive of an allergic disease.

The human leukocyte antigen (HLA) class II antigens (DR, DQ, DP) play a key role in antigen presentation to Tlymphocytes and thus influence the specificity of the immune response. These HLA class II molecules are highly polymorphic. Many associations between class II alleles and common aeroallergens have been investigated [4-15]. Specific epitopes of allergens have been identified at the amino acid level and have been shown to be presented by specific HLA DR and DQ gene products [11].

Little is known about host risk factors for the development of occupational asthma due to these small molecular weight compounds [2, 3]. Recently, HLA class II genetic markers were found to be associated with susceptibility or resistance to isocyanate-induced asthma [16-18]. Because there is considerable similarity between the two types of occupational asthma, the distribution of DRB1 and DQB1 HLA class II alleles in patients with asthma due to occupational exposure to Western red cedar were studied in order to examine a possible association of these genetic markers with susceptibility to this disease.

\section{Materials and methods}

Subjects

Fifty-six Caucasian patients who were diagnosed with WRCA by specific challenge test were enrolled consecutively into the study. All tests took place during a follow-up visit between September 1993 and August 1995 at the Respiratory Clinic of the University of British Columbia (Vancouver, Canada). As control subjects, 63 Caucasian sawmill workers who were exposed to western red cedar dust and did not have any respiratory disease were studied. The characteristics of the study subjects are shown in table 1. The patients were significantly older than the control subjects (43.7 \pm 9.9 yrs versus $37.6 \pm 10.8$ yrs) although the control subjects were exposed to red cedar dust for a longer period of time ( $10 \pm 10.2$ yrs versus $6 \pm 7.2 \mathrm{yrs})$. Forty-seven per cent of patients had a late asthmatic reaction, $45 \%$ a dual or biphasic reaction and the remaining had immediate asthmatic reaction alone on inhalation challenge testing with plicatic acid.

White blood cell isolation and deoxyribonucleic acid extraction

Mononuclear cells isolated from peripheral blood, were purified using Histopaque density gradient separation as described previously [19]. Cells resuspended in phosphate 
Table 1. - Characteristics of study subjects

\begin{tabular}{lcc}
\hline & Patients & $\begin{array}{c}\text { Control } \\
\text { subjects }\end{array}$ \\
\hline $\mathrm{n}$ & 56 & 63 \\
Age yrs & $43.7 \pm 9.9$ & $37.6 \pm 10.8$ \\
Duration of exposure before onset & $6.1 \pm 7.2$ & NA \\
$\quad$ of symptoms & & \\
Duration of employment yrs & & 10.2 \\
Mean & & 36 \\
Max & $2.7 \pm 3.4$ & 19 \\
Duration of symptoms yrs & 50 & \\
Atopy \% & & 3 \\
Smoking habit \% & 42 & 34 \\
$\quad$ Nonsmokers & 56 & 27 \\
Exsmokers & 2 & 100 \\
Current smokers & 98 & - \\
Sex \% male & & - \\
Types of asthmatic reaction \% & 7 & - \\
Immediate & 47 & \\
Late & 45 & \\
Dual & & \\
\hline
\end{tabular}

Data are presented as absolute numbers or mean \pm SD. NA: not applicable.

buffered saline were stored in aliquots at $-80^{\circ} \mathrm{C}$ until analysis. Genomic deoxyribonucleic acid (DNA) was extracted using the Qiagen kit according to the suppliers protocol (Qiagen Inc., Valencia, CA, USA).

\section{Human leukocyte antigen DRB1 and DQB1 typing}

DNA typing for the DRB1 and DQB1 alleles was performed using modified, group specific polymerase chain reaction amplifications of the second exon of the DRB1 [20, 21] and DQB1 [22] locus, followed by restriction digestion of the amplified sample and polyacrylamide gel electrophoresis. Restricted patterns for all published DRB1 and DQB1 second exon sequences [23] were predicted. Twenty-seven of the 42 DRB1 alleles and 13 of the 14 DQB1 alleles typed for, were observed in this study. Haplotype analysis was performed on the basis of assignment of the most common haplotypes in the Caucasian population [24]. In the 119 samples observed there were 32 haplotypes, with only three $(1.7 \%)$ rare haplotypes.

\section{Statistical analysis}

The statistical significance of differences in frequency of individual major histocompatibility complex alleles and haplotypes in patients and control subjects was determined by Fisher's exact test (two-tailed probability (p) value) using Instat software (Graph Pad, San Diego, CA, USA). The strength of an association was indicated by odds ratio (OR) with 95\% confidence interval. The p-values were presented without $(\mathrm{p})$ or with correction for number of comparisons [25].

\section{Results}

The distribution of DRB1 and DQB1 alleles in patients and control subjects is shown in table 2 . The frequency of DQB $1 * 0302$ was significantly increased in patients compared to healthy control subjects $(19.6 \%$ versus $4.7 \%$, $\mathrm{p}=0.02, \mathrm{OR}=4.9)$ as was the frequency of DQB $1 * 0603$ ( $23.2 \%$ versus $9.4 \%, \mathrm{p}=0.0484, \mathrm{OR}=2.9)$. In contrast, the frequency of DQB $1 * 0501$ was significantly reduced in patients $(10.7 \%$ versus $28.1 \%, \mathrm{p}=0.0213, \mathrm{OR}=0.3)$ and indicates a protective effect. Three of the six patients that typed DQB $1 * 0501$ on one allele typed with a susceptible allele on the second chromosome.

DQB $1 * 0302$ allele is in linkage disequilibrium with $\mathrm{DRB} 1 * 4$, and $\mathrm{DQB} 1 * 0603$ is in linkage disequilibrium with DRB1*1301. A small increase in the frequencies of DRB1*0401 and DRB1*1301 among patients was observed, but the increases were not statistically significant. DQB $1 * 0501$ is in linkage disequilibrium with DRB1* $0101, * 0102, * 0103$ and DRB $1 * 1001$. The frequency of

Table 2. - Frequency of human leukocyte antigen class II alleles in patients and control subjects

\begin{tabular}{|c|c|c|c|c|c|c|c|}
\hline \multirow[t]{2}{*}{$\begin{array}{l}\text { Class II } \\
\text { allele }\end{array}$} & \multicolumn{2}{|c|}{$\begin{array}{c}\text { Patients } \\
\mathrm{n}=56\end{array}$} & \multicolumn{2}{|c|}{$\begin{array}{c}\text { Control } \\
\text { subjects } \\
n=63\end{array}$} & \multirow[t]{2}{*}{ p-value* } & \multirow[t]{2}{*}{$\mathrm{OR}$} & \multirow[t]{2}{*}{$95 \% \mathrm{CI}$} \\
\hline & No. & $\%$ & No. & $\%$ & & & \\
\hline \multicolumn{8}{|l|}{ DRB1 } \\
\hline 0101 & 4 & 7.1 & 15 & 23.4 & 0.0222 & 0.25 & $0.08-0.79$ \\
\hline 0102 & 1 & 1.8 & 1 & 1.6 & & & \\
\hline 0103 & 1 & 1.8 & 2 & 3.1 & & & \\
\hline 1501 & 19 & 33.9 & 22 & 34.4 & & & \\
\hline 1502 & 0 & 0.0 & 1 & 1.6 & & & \\
\hline 1601 & 4 & 7.1 & 1 & 1.6 & & & \\
\hline 1602 & 0 & 0.0 & 1 & 1.6 & & & \\
\hline 0301 & 9 & 16.1 & 12 & 18.8 & & & \\
\hline 0401 & 12 & 21.4 & 9 & 14.1 & & & \\
\hline 0402 & 1 & 1.8 & 0 & 0.0 & & & \\
\hline 0403 & 1 & 1.8 & 0 & 0.0 & & & \\
\hline 0404 & 2 & 3.6 & 4 & 6.3 & & & \\
\hline 0405 & 1 & 1.8 & 0 & 0.0 & & & \\
\hline 0408 & 2 & 3.6 & 1 & 1.6 & & & \\
\hline 1101 & 7 & 12.5 & 7 & 10.9 & & & \\
\hline 1102 & 1 & 1.8 & 0 & 0.0 & & & \\
\hline 1104 & 2 & 3.6 & 0 & 0.0 & & & \\
\hline 1301 & 9 & 16.1 & 5 & 7.8 & & & \\
\hline 1302 & 3 & 5.4 & 4 & 6.3 & & & \\
\hline 1305 & 0 & 0.0 & 1 & 1.6 & & & \\
\hline 1401 & 5 & 8.9 & 4 & 6.3 & & & \\
\hline 1402 & 0 & 0.0 & 1 & 1.6 & & & \\
\hline 0701 & 18 & 32.1 & 21 & 32.8 & & & \\
\hline 0801 & 1 & 1.8 & 4 & 6.3 & & & \\
\hline 0802 & 1 & 1.8 & 1 & 1.6 & & & \\
\hline 0901 & 1 & 1.8 & 2 & 3.1 & & & \\
\hline 1001 & 0 & 0.0 & 1 & 1.6 & & & \\
\hline \multicolumn{8}{|l|}{ DQB1 } \\
\hline 0501 & 6 & 10.7 & 18 & 28.1 & 0.0213 & 0.3 & $0.11-0.82$ \\
\hline 0502 & 4 & 7.1 & 2 & 3.1 & & & \\
\hline 0503 & 5 & 8.9 & 4 & 6.3 & & & \\
\hline 0504 & 0 & 0.0 & 2 & 3.1 & & & \\
\hline 0601 & 0 & 0.0 & 1 & 1.6 & & & \\
\hline 0602 & 16 & 28.6 & 21 & 32.8 & & & \\
\hline 0603 & 13 & 23.2 & 6 & 9.4 & 0.0484 & 2.9 & $1.01-8.17$ \\
\hline 0604 & 2 & 3.6 & 4 & 6.3 & & & \\
\hline 0201 & 23 & 41.1 & 25 & 39.1 & & & \\
\hline 0301 & 14 & 25.0 & 17 & 26.6 & & & \\
\hline 0302 & 11 & 19.6 & 3 & 4.7 & 0.0201 & 4.9 & $1.28-18.56$ \\
\hline 0303 & 8 & 14.3 & 9 & 14.1 & & & \\
\hline 0304 & 1 & 1.8 & 0 & 0.0 & & & \\
\hline 0402 & 3 & 5.4 & 7 & 10.9 & & & \\
\hline
\end{tabular}

OR: odds ratio; $95 \% \mathrm{CI}$ : $95 \%$ confidence interval. *: only $\mathrm{p}<0.05$ are listed. None of the p-values with correction for number of comparisons were significant. 
DRB $1 * 0101$ was decreased in patients as compared to control subjects $(10.7 \%$ versus $28.6 \%, \mathrm{p}=0.022, \mathrm{OR}=$ 0.25 ). Analysis of the DRB1-DQB1 haplotype frequencies revealed DRB $1 * 0401-\mathrm{DQB} 1 * 0302$ as the most susceptible haplotype in development of asthma due to red cedar $(\mathrm{p}=0.012, \mathrm{OR}=10.33)$, while the association of DQB1* 0302 with any of the DRB1*4 $(* 0401 / 2 / 4$ or 8$)$ also revealed high OR and the most significant $p$-value $(p=0.003$, $\mathrm{OR}=8.3)$. The presence of the haplotype DRB1*0101$\mathrm{DQB} 1 * 0501$ appeared to confer protection $(\mathrm{p}=0.038, \mathrm{OR}=$ $0.27)$. The increased frequency of DRB $1 * 1301-\mathrm{DQB} 1 *$ 0603 in patients was not significant. The rare haplotype DRB1*1501-DQB1*0603 was observed in three patients.

The frequencies of DR and DQ alleles in patients with late asthmatic reaction alone were not different from those with dual asthmatic reaction (data not shown).

\section{Discussion}

In this study, the authors have found that the frequency of the HLA class II alleles DQB $1 * 0302$ and DQB $1 * 0603$ was significantly increased among patients compared to exposed healthy control subjects while the frequency of DQB $1 * 0501$ was significantly decreased. Forty-three per cent of the patients had one of the two susceptibility alleles, while only $13 \%$ of the healthy exposed control subjects did. After correction was performed for multiple comparisons, these differences between patients and control subjects were no longer significant. However, the application of such corrections remains controversial in view of the fact that the allele frequencies tested are not independent [26] and this is not normally employed in this setting [16, 18]. BALBONI et al. [17] employed a correction taking into account alleles previously reported as being associated to toluene diisocyanate (TDI)-induced asthma [16] and thus the corrected $\mathrm{p}$-values were obtained by multiplying by two instead of 14 (number of DQB1 alleles).

The frequency of the DRB1*0401-DQB1*0302 haplotype was found to be increased and the frequency of the DRB $1 * 0101-D Q B 1 * 0501$ haplotype was reduced in patients compared to the control subjects. It is however possible, that these DRB1-DQB1 haplotypes are a part of conserved extended HLA haplotypes on chromosome six and that they reflect a linkage disequilibrium with some alleles in close proximity [27]. One possible candidate is the tumour necrosis factor (TNF) locus located telomeric to the DRB1 locus. Elevated levels of TNF- $\alpha$ proteins are observed in inflammatory processes. MAstrelli et al. [28] reported increased levels of TNF- $\alpha$ in the airway mucosa of subjects with asthma induced by TDI. Centromeric to the DQB1 allele, lies the polymorphic DPB1 locus of the HLA class II. DPB1 allele typing was not performed because the DPB $1 * 0401$ allele is found in $80 \%$ of Caucasians and many other DPB1 alleles occur at very low frequencies. In order to observe statistically significant differences, a much larger control sample would be required.

Studies in patients with isocyanate-induced asthma have also shown that alleles within the HLA class II region appear to be associated with an increased or decreased risk of disease. BIGNON et al. [16] found that DQB1*0503 and the allelic combination DQB $*^{*} 0201 / 0301$ were associated with increased susceptibility to the disease while the presence of DQB1*0501 and the DQA*0101-DQB1*
0501-DR1 haplotype conferred significant protection to exposed healthy control subjects. In contrast, a recent study in 10 patients with isocyanate-induced asthma [29] failed to show any association with HLA class II antigens. HLA class II typing in this study was performed only at low resolution. BALBONI et al. [17] and MAPP et al. [18] investigated DQA1 and DQB1 association with TDIinduced asthma. These reports reconfirmed the positive association of asthma with DQB $1 * 0503$ and a negative association with DQB $1 * 0501$ allele reported by BIGNON et al. [16]. DQB $1 * 0503$ and DQB $1 * 0501$ differ by a single amino acid residue 57 (aspartic acid in DQB $1 * 0503$ and valine in DQB1*0501), and the group postulated that the susceptibility to, or protection from, TDI-induced asthma appears to be related to this difference. The present study found that the alleles, DQB $1 * 0501$ conferring protection, and DQB1*0603 and DQB1*0302 responsible for disease susceptibility, differ by several amino acids. However, it is of interest to note that the HLA allele DQB1* 0501 appears to confer protection against the development of both red cedar asthma and isocyanate-induced asthma [16-18], although the susceptibility alleles are different in these disorders.

The clinical features of occupational asthma induced by isocyanates and red cedar are similar. For example, inhalation provocation tests with these two agents in sensitized subjects induced isolated late or dual asthmatic reactions while isolated immediate asthmatic reactions are rare [1, 2]. The mechanism of occupational asthma due to these two agents is not clear. In WRCA, specific IgE antibodies to plicatic acid-human serum albumin conjugate (PAHSA) have been detected in only $20 \%$ of the patients [30]. However, incubation of granulocytes from patients with WRCA with anti-IgE failed to inhibit the release of histamine when challenged with plicatic acid [31]. These findings suggest that specific IgE antibodies may only be a marker of exposure and may not be responsible for the pathogenesis of the disease. Recently, activated CD4+ cells were demonstrated in the bronchial mucosa of these patients [32]. Also, the lymphocytes of some patients with WRCA showed proliferation when stimulated with PA-HSA conjugate suggesting that T-lymphocytes may play an important role in the pathogenesis of WRCA [33]. The findings of this study suggest that HLA class II alleles are associated with susceptibility to development of WRCA and further strengthen the hypothesis that cellular immune mechanisms may play a role in its pathogenesis. It is possible that plicatic acid acts as a hapten and binds to a protein or peptide and is recognized by Tlymphocytes as a foreign antigen. The recent report of CD8+ rather than CD4+ T-cells cloned from the bronchial mucosa of patients with isocyanate-induced asthma [34] suggests that HLA class I alleles should be studied in these patients. In recent years genome-wide searches have shown that many genetic loci predispose to asthma. Identification of other candidate genes will help to achieve a better understanding of susceptibility to occupational asthma caused by western red cedar.

While the degree of exposure is the most important determinant for the development of occupational asthma, host susceptibility factors appear to be of importance. Given the same degree of exposure, only a small proportion $(\sim 5 \%)$ of exposed subjects develop the disease. Atopy has been shown to be an important risk factor in occupational 
asthma due to high molecular weight allergens [1], but not in occupational asthma due to small molecular weight compounds, such as isocyanates and plicatic acid $[1,3]$. This study suggests that genetic factors such as human leukocyte antigen class II antigens may predispose individuals to the development of occupational asthma.

\section{References}

1. Chan-Yeung M, Malo JL. Aetiologic agents in occupational asthma. Eur Respir J 1991; 7: 346-371.

2. Chan-Yeung M, Lam S, Koerner S. Clinical features and natural history of occupational asthma due to western red cedar (Thuja plicata). Am J Med 1982; 72: 411-415.

3. Mapp CE, Boschetto P, Dal Vecchio L, Mastrelli P, Fabbri LM. Occupational asthma due to isocyanates. Eur Respir J 1988; 1: 273-279.

4. Ansari AA, Freidhoff LR, Meyers DA, Bias WB, Marsh DG. Human immune responsiveness to Lolium perenne pollen allergen Lol p III (rye III) is associated with HLADR3 and DR5. Hum Immunol 1989; 25: 59-71.

5. Marsh DG, Huang SK. Molecular genetics of human immune responsiveness to pollen allergens. Clin Exp Allergy 1991; 21: (Suppl. 1), 168-172.

6. Yssel H, Johnson KE, Schneider PV, et al. T cell activation-inducing epitopes of the house dust mite allergen Der $\mathrm{p}$ I. Proliferation and lymphokine production patterns by Der p I-specific CD4+ T cell clones. J Immunol 1992; 148: 738-745.

7. Fischer GF, Pickl WF, Fae I, et al. Association between IgE response against Bet $\mathrm{v}$ I, the major allergen of birch pollen, and HLA-DRB alleles. Hum Immunol 1992; 33: 259-265.

8. Reid MJ, Nish WA, Whisman BA. HLA-DR4-associated nonresponsiveness to mountain-cedar allergen. J Allergy Clin Immunol 1992; 89: 593-598.

9. Blumenthal M, Marcus-Bagley D, Awdeh Z, Johnson B, Yunis EJ Alper CA. HLA-DR2, [HLA-B7, SC31, DR2], and [HLA-B8, SC01, DR3] haplotypes distinguish subjects with asthma from those with rhinitis only in ragweed pollen allergy. J Immunol 1992; 148: 411-416.

10. Cardaba B, Vilches C, Martin E, et al. DR7 and DQ2 are positively associated with immunoglobulin-E response to the main antigen of olive pollen (Ole e I) in allergic patients. Hum Immunol 1993; 38: 293-299.

11. Verhoef A, Higgins JA, Thorpe CJ, et al. Clonal analysis of the atopic immune response to the group 2 allergen of Dermatophagoides spp.: identification of HLA-DR and -DQ restricted T cell epitopes. Int Immunol 1993; 5: 1589-1597.

12. Young RP, Dekker JW, Wordsworth BP, et al. HLA-DR and HLA-DP genotypes and immunoglobulin E responses to common major allergens. Clin Exp Allergy 1994; 24: 431-439.

13. Tautz C, Rihs HP, Thiele A, et al. Association of class II sequences encoding DR1 and DQ5 specificities with hypersensitivity to chironomid allergen Chi t I. J Allergy Clin Immunol 1994; 93: 918-925.

14. D'Amato M, Scotto d'Abusco A, Maggi E, et al. Association of responsiveness to the major pollen allergen of Parietaria officinalis with HLA-DRB1* alleles: a multicenter study. Hum Immunol 1996; 46: 100-106.

15. Cardaba B, De Pablo R, Vilches C, et al. Allergy to olive pollen: T-cell response from olive allergic patients is restricted by DR7-DQ2 antigens. Clin Exp Allergy 1996; 26: 316-322.

16. Bignon J, Aron Y, Kopferschmitt MC, et al. HLA class II alleles in isocyanate-induced asthma. Am J Respir Crit Care Med 1994; 149: 71-75.
17. Balboni A, Baricordi OR, Fabbri LM, Gandini E, Ciaccia A, Mapp CE. Association between toluene diisocyanateinduced asthma and DQB1 markers: a possible role for aspartic acid at position 57. Eur Respir J 1996; 9: 207-210.

18. Mapp CE, Balboni A, Baricordi R, Fabbri LM. Human leukocyte antigen associations in occupational asthma induced by isocyanates. Am J Respir Crit Care Med 1997; 156: S139-S143.

19. Chang JH, Chan $\mathrm{H}$, Quirce $\mathrm{S}$, et al. In vitro T-lymphocyte response and house dust mite-induced bronchoconstriction. J Allergy Clin Immunol 1996; 98: 922-931.

20. Yunis I, Salazar M, Yunis EJ. HLA-DR generic typing by AFLP. Tissue Antigens 1991; 38: 78-88.

21. Horne C, Keown PA. Rapid DNA typing for class II HLA antigens: subtyping of DRw52-associated DRB1 alleles. Tissue Antigens 1993; 41: 243-248.

22. Nomura N, Ota M, Tsuji K, Inoko H. HLA-DQB1 genotyping by a modified PCR-RFLP method combined with group-specific primers. Tissue Antigens 1991; 40: 229-243.

23. Marsh SG, Bodmer JG. HLA class II region nucleotide sequences, 1995. Tissue Antigens 1995; 46: 258-280.

24. Imanishi T, Akaza T, Kimura A, et al. Allele and haplotype frequencies for HLA and complement loci in various ethnic groups. In: 11th International Histocompatibility Workshop and Conference. Yokohama, Japan, Oxford University Press, 1991; pp. 1063-1110.

25. Dyer P, Warren A. Design and interpretation of studies of major histocompatibility complex in diseases. In: Lechler $\mathrm{R}$, ed. HLA and disease. London, UK, London Academic Press, 1994; pp. 93-121.

26. Busson M, Prevost P. Usual statistical methods for studying HLA-disease associations and linkages. Pathol Biol 1986; 34: 711-714.

27. D'Alonso S, Cappello N, Carcassi C, Fasano ME, Momigliano-Richardi P. Microsatellites in the HLA central region are markers of HLA conserved extended haplotypes. In: 12th International Histocompatibility Workshop and Conference. Paris, France, Sevres, EDK, 1997; pp. 125-127.

28. Maestrelli P, di Stefano A, Occari P, et al. Cytokines in the airway mucosa of subjects with asthma induced by toluene diisocyanate. Am J Respir Crit Care Med 1995; 151: 607612.

29. Bernstein JA, Munson J, Lummus ZL, Balakrishnan K, Leikauf $\mathrm{G}$. T-cell receptor $\mathrm{V}$ beta gene segment expression in diisocyanate-induced occupational asthma. J Allergy Clin Immunol 1997; 99: 245-250.

30. Tse KS, Chan H, Chan-Yeung M. Specific IgE antibodies in workers with occupational asthma due to western red cedar. Clin Allergy 1982; 12: 249-258.

31. Frew A, Chan H, Dryden P, Salari H Lam S Chan-Yeung M. Immunologic studies of the mechanisms of occupational asthma caused by western red cedar. $J$ Allergy Clin Immunol 1993; 92: 466-478.

32. Frew AJ, Chan H, Lam S, Chan-Yeung M. Bronchial inflammation in occupational asthma due to western red cedar. Am J Respir Crit Care Med 1995; 151: 340-344.

33. Frew A, Chang JH, Chan H, et al. T-lymphocyte responses to plicatic acid-human serum albumin conjugate in occupational asthma caused by western red cedar. $J$ Allergy Clin Immunol 1998; 101: 841-847.

34. Maestrelli P, Del Prete GF, De Carli M, et al. Activated CD8 T-lymphocytes producing interferon-gamma and interleukin-5 in bronchial mucosa of subjects sensitized to toluene diisocyanate (TDI). J Allergy Clin Immunol 1993; 91: 220 . 